\title{
Modeling of the Vegetable Oil Blends Composition
}

\author{
Olga S. Voskanyan ${ }^{1}$ \\ Department "Technology of Products from Plant Materials, \\ Perfumes and Cosmetics", K.G. Razumovsky Moscow State \\ University of Technologies and Management (The First \\ Cossack University), Moscow, Russian Federation
}

Igor A. Nikitin ${ }^{2}$

Department "Technology of Grain Processing, Bakery, Pasta and Confectionery Industries"

K.G. Razumovsky Moscow State University of Technologies and Management (The First Cossack University)

Moscow, Russian Federation

\author{
Marina A. Nikitina ${ }^{3}$ \\ V.M. Gorbatov Federal Research Center for Food Systems \\ Moscow \\ Russian Federation
}

\author{
Maria V. Klokonos ${ }^{4}$ \\ Department "Technology of Grain Processing, Bakery, Pasta \\ and Confectionery Industries", K.G. Razumovsky Moscow \\ State University of Technologies and Management (The First \\ Cossack University), Moscow, Russian Federation
}

\author{
Daria A. Guseva ${ }^{5}$ \\ Department "Technology of Grain Processing, Bakery, Pasta \\ and Confectionery Industries" \\ K.G. Razumovsky Moscow State University of Technologies \\ and Management (The First Cossack University) \\ Moscow, Russian Federation
}

Igor V. Zavalishin ${ }^{6}$

K.G. Razumovsky Moscow State University of Technologies and Management (The First Cossack University) Moscow, Russian Federation

optimizing the composition of multicomponent food products can be described mathematically [1]. Currently, food design principles are based on modern knowledge in the field of physiology, molecular medicine and food chemistry, and they are based on the concept of a balanced diet, which determines the correlative relationship between food absorption and the degree of balance of its chemical composition.

Therefore, creation of new generation fatty products of functional and specialized purposes, balanced in their fatty acid composition, for the oil and fat industry is one of the promising areas of innovative development of the food industry [2]. Based on the variation of ratios of the known vegetable oils in the blends, you can create various products with desired functional and therapeutic properties [3, 4].

The aim of the work was to develop an integrated approach to creating compounding blends of vegetable oils, optimized by the composition of polyunsaturated fatty acids for healthy and therapeutic and preventive nutrition, in particular with a given ratio of omega- 6 / omega- $3=5 / 1$ polyunsaturated fatty acids using the "brute force" method.

II. Formulation AND ANALYSis OF the Problem of DEVELOPMENT OF OIL BLENDS WITH BALANCED FATTY ACID

\section{COMPOSITION}

Vegetable oils are vital products that have a large and diverse use in the human diet [5]. Compared with carbohydrates and proteins, lipids have a higher nutritional and energy value, so nutritionists attach great importance to the issue of increasing the proportion of vegetable oils used in food, because they have a specific physiological effect due to the content of essential polyunsaturated acids positively affecting the human body. 
Excess intake of fats rich in saturated fatty acids contributes to the development of atherosclerosis and coronary heart disease, obesity, gallstone disease. At the same time, modern man lacks polyunsaturated fatty acids (PUFAs), the source of which is mainly vegetable oils [6].

Omega-3 and omega-6 PUFA are essential fatty acids that the human body cannot synthesize on its own and can only be obtained from food. However, the effect of these fatty acids on the human body is manifested quite differently [7]. Since Omega-3 and Omega-6 PUFAs compete for the same delta-6desaturase enzyme, with the help of which they are converted to longer-chain acids, the ratio of these fatty acids has a significant effect on the ratio of eicasoids that act as tissue hormones in the body, and, therefore, significantly affects the metabolic processes in the body.

According to numerous studies, it has been established that these fatty acids should come from food in the ratio of omega- 6 / omega-3, equal to 8-9 / 1 for healthy people, and in the ratio $5 / 1$ for therapeutic and preventive nutrition, while modern man eats omega-3 with food 5-6 times less [8]. In this regard, the development of blends containing the optimal ratio of omega- 6 / omega-3 fatty acids based on various vegetable oils for therapeutic and prophylactic nutrition is an urgent task, and the creation of software tools to automate this process will contribute to its operational solution.

In the process of developing the composition of blends, it is advisable to apply computer modeling methods that allow to determine functional properties more accurately and establish the optimal percentage of ingredients that make up the blends $[9,10]$.

For the preparation of new science-based blends of vegetable oils used in therapeutic and preventive nutrition, methods of mathematical modeling of the selection of the composition, in particular the brute force method, have recently been used.

To solve the problem, it is first necessary to analyze and select vegetable oils with a high content of omega-3 PUFA. Next, you need to choose a blend composition that would meet the medical and biological requirements and restrictions. To do this, you can use the process of optimizing the composition of new blends of vegetable oils on the ratio of omega-6 PUFA: omega-3, which is 10: 1 for healthy people, and 5: 1 for therapeutic and preventive nutrition. For this purpose, it is necessary to model the component composition of vegetable oil blends with the content of optimal fatty acid composition for therapeutic and preventive nutrition (omega-6: omega-3 = 5: 1) that meets the relevant requirements for physical and chemical quality indicators, as well as having organoleptic properties, satisfying tastes of most consumers.

The solution of the task consists of three stages:

- Input of the initial data on the components of blends of oils and PUFAs (omega-6 and omega-3 acids);

- The choice of the objective function by the ratio of PUFA;

- Carrying out the necessary calculations.
TABLE. I. FATTY ACID COMPOSITION OF VEGETABLE OILS

\begin{tabular}{|l|l|l|l|l|l|l|}
\hline \multirow{2}{*}{$\begin{array}{l}\text { Name of } \\
\text { PUFA }\end{array}$} & \multicolumn{5}{|l|}{ The content of PUFA in vegetable oil,\% of the total } \\
\cline { 2 - 7 } & $\begin{array}{l}\text { Sunflower } \\
\text { oil }\end{array}$ & $\begin{array}{l}\text { Mustard } \\
\text { oil }\end{array}$ & $\begin{array}{l}\text { Pumpkin } \\
\text { oil }\end{array}$ & $\begin{array}{l}\text { Linseed } \\
\text { oil }\end{array}$ & $\begin{array}{l}\text { Wheat } \\
\text { germ oil }\end{array}$ & $\begin{array}{l}\text { Milk } \\
\text { Thistle } \\
\text { oil }\end{array}$ \\
\hline $\begin{array}{l}\text { Linoleic } \\
\text { (omega-6) }\end{array}$ & 50.90 & 17.80 & 53.10 & 15.89 & 57.00 & 55.60 \\
\hline $\begin{array}{l}\text { Arachidonic } \\
\text { (omega-6) }\end{array}$ & 0.50 & 0.00 & 0.30 & 0.00 & 0.00 & 2.00 \\
\hline $\begin{array}{l}\text { 6-Linolenic } \\
\text { (omega-3) }\end{array}$ & 0.30 & 5.60 & 8.00 & 60.00 & 5.60 & 3.00 \\
\hline
\end{tabular}

The selection of components of the composition of new oil blends was carried out on the basis of the analysis of literature data [11]. Characteristics of the raw ingredients of blends of oils for therapeutic and prophylactic nutrition are presented in Table I.

Analyzing Table I, first of all it should be noted that sunflower and pumpkin oils, as well as wheat germ oil and milk Thistle oil contain significant amounts of linoleic acid, and at the same time, arachidonic acid is practically absent in them. Considering the group of omega- 3 acids, it is necessary to highlight linseed oil, which contains $60.0 \% \alpha$-linolenic acid [12]. The rest of the studied oils are characterized by a low content of this acid-ranging from $0.3 \%$ (in sunflower oil) to $8.0 \%$ (in pumpkin oil).

Such an incomplete presence of acids of the omega- 6 and omega-3 groups poses the problem of optimizing the fatty acid composition for the development of blends of vegetable oils for therapeutic and prophylactic purposes [13]. At the same time, they are prepared on the basis of optimal ratios of linoleic and $\alpha$-linolenic acids, since other acids are contained in the blend oils in an insignificant amount and have no significant effect on the balance of acids $[14,15]$.

The solution of the problem is possible by modeling the composition of the blends using the exhaustive "brute force" method with a numerical value of 5: 1 as the objective function (the ratio of omega-6 to omega-3 as 5: 1) [16].

\section{Algorithm of Scientific RESEARCH SyStem Work. MATHEMATICAL FORMALIZATION}

The task was implemented by the method of complete enumeration with a given accuracy of $1 \%$.

A complete search (or the "brute force" method) is a method for solving mathematical problems. Refers to a class of methods for finding solutions by exhaustion of all sorts of variants [17]. The complexity of the method depends on the number of all possible solutions to the problem. The problem considered in the framework of our study belongs to the NP class, therefore it can be solved by this method.

The algorithm of the proposed method is presented in Fig. 1.

Pointers allow you to restore the path back after finding the recipe composition at the i-th iteration step. In step 5 of the presented algorithm, the recipe composition is placed at the end of the Open list. 


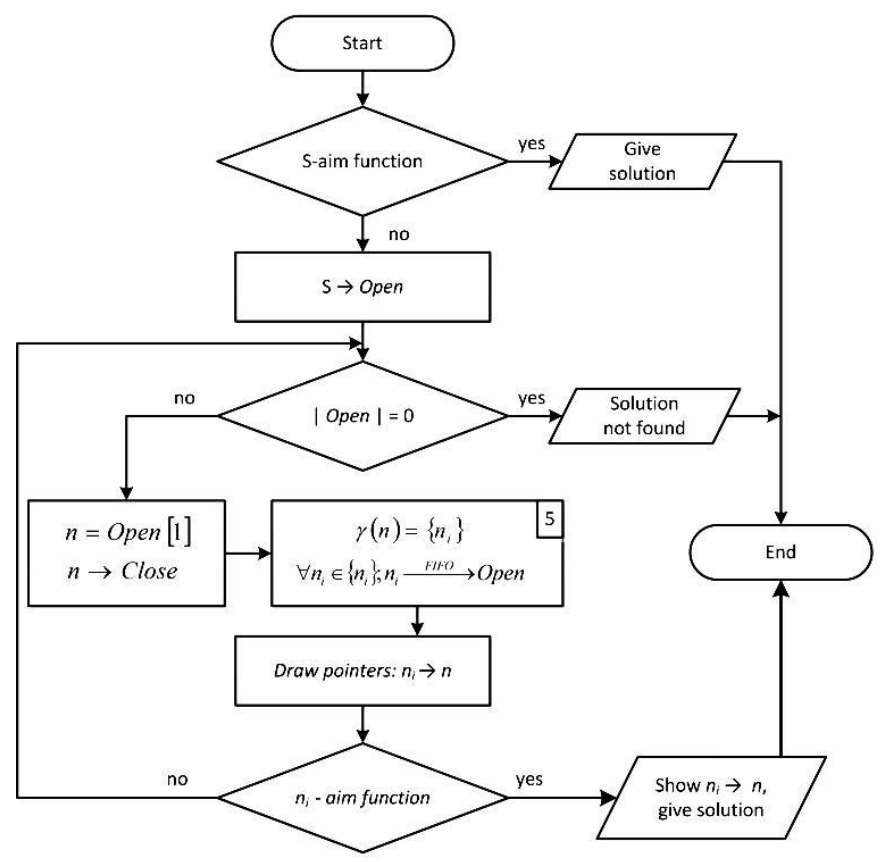

Fig. 1. Block Diagram of the "Brute Force" Method, where "Open" is a List of Prescription Compositions to which the Operator $\gamma$ has not yet been Applied (Optimization Criterion and Constraints); "Close"-a List of Prescription Compositions to which the $\gamma$ Operator has Already been Applied.

To solve the problem of optimizing the composition of plant blends in various formulations and combinations of nonlinear criteria and restrictions we perform simulation modeling with playing out all possible combinations of the initial components of the formulation, followed by checking the restrictions and calculating the criteria using the algorithm of the brute force method.

The search for the optimal blend of vegetable oils from ncomponents begins with the choice of the mass fraction of the first component $\mathrm{X}_{1}$ and the search of other values that mimic all combinatorial versions of the $n$-component product formulation. Further, if $\mathrm{X}_{\mathrm{j}}$ satisfies the boundary conditions, then the next acceptable ratio is memorized and the cycle goes to the next relation for $j=j+1$-th component. When $X_{j}<\min _{j}$, its fractional ratio with subsequent components increases by the step size, and in the case of $X_{j}>\max _{j}$, it returns to the initial $\mathrm{jth}$ ratio and continues the previous cycle for $\mathrm{j}=\mathrm{j}-1$ th component with a starting value.

After selecting the specified ratios of all the components of the recipe so that the mass fractions in the total amount to one, the parametric and balance constraints are checked with an accumulation of permissible options evaluated by the objective function and the choice of the best alternative solution.

The algorithm for the sequential formation of the ingredients included in the recipe allows you to find the optimal model as follows:

1) The first combination of recipes that satisfies all the boundary and balance constraints is considered, and its value of the criterion $F_{1}(x)$ is calculated. This recipe is considered optimal and its parameters are captured.
2) The second composition of the formulation that satisfies all the boundary and balance constraints is considered, and its value of the criterion $F_{2}(x)$ is calculated. If $F_{2}(x)<F_{1}(x)$, then the second composition is optimal, its recipe is captured, and the recipe of the previous model is deleted. If $F_{1}(x)<=F_{2}(x)$, then the previous formulation remains optimal and the next model is considered.

3) The process of reviewing new formulation compositions and comparing the quality of the new formulation and the best in the previous step continues until all possible combinations of the formulation compositions are considered.

As a source of data, a list of raw materials was used (Table I) for modeling the composition of oil blends. Omega-6 and omega- 3 values in 1 gram of lipid were used as the coefficients of the objective function. In addition, the study took into account the boundary data for each component in the composition of the blends.

When developing options, the choice of the minimum and maximum dosage of the components in the blends was determined experimentally.

Analysis of the results of the research allowed us to establish the permissible limits for the variation of the boundary conditions for vegetable oils in the blends (Table II).

The analysis of the compatibility of the aromatic characteristics of the vegetable oils under consideration served to compile three blend compositions:

1) blend: mustard oil, pumpkin oil and milk thistle oil;

2) blend: sunflower oil, linseed oil and milk thistle oil;

3) blend: sunflower oil, wheat germ oil and milk thistle oil.

The mathematical formalization of the task in generalized form is as follows:

objective function

$\Phi(X)=\frac{\omega_{6}}{\omega_{3}} \rightarrow k$

under restrictions

$$
\begin{aligned}
& \omega_{\mathrm{i}}=\sum_{\mathrm{i}=1}^{\mathrm{n}} \omega_{\mathrm{i}} \mathrm{x}_{\mathrm{i}} \\
& \sum_{\mathrm{i}=1}^{\mathrm{n}} \mathrm{x}_{\mathrm{i}}=1, \mathrm{x}_{\mathrm{i}}>0
\end{aligned}
$$

where $\omega_{i}$ is the content of PUFAs of the i-th omega family ( $i=3$ - oils of the omega- 3 family, $i=6$ - oils of the omega- 6 family);

$\mathrm{x}_{\mathrm{i}}$ is the mass fraction of the $\mathrm{i}$-th vegetable oil in the blend;

$\mathrm{k}$ is the ratio to which the ratio of omega-6 (ळ6) to omega-3 (®3) should tend, in our case 5:1. 
TABLE. II. PERMISSIBLE LIMITS OF VARIATION OF THE BOUNDARY CONDITIONS FOR VEGETABLE OILS IN THE BLENDS' COMPOSITION

\begin{tabular}{|l|l|l|}
\hline Oil name & min, \% & $\max , \boldsymbol{\%}$ \\
\hline Sunflower oil & 0 & 60 \\
\hline Mustard oil & 0 & 60 \\
\hline Linseed oil & 0 & 30 \\
\hline Milk Thistle oil & 0 & 60 \\
\hline Wheat germ oil & 0 & 90 \\
\hline Pumpkin oil & 0 & 40 \\
\hline
\end{tabular}

For our particular case, mathematical models are presented in three alternative versions as follows:

\section{1) For the first blend}

$$
\begin{aligned}
& \omega 6 / \omega 3=5 / 1 \\
& \omega_{6}=17.8 X_{1}+53.1 X_{2}+55.6 X_{3} \\
& \omega_{6}=5.6 X_{1}+8.0 X_{2}+3.0 X_{3}
\end{aligned}
$$

2) For the second blend

$$
\begin{aligned}
& \omega 6 / \omega 3=5 / 1 \\
& \omega_{6}=51.5 X_{1}+15.89 X_{2}+55.6 X_{3} \\
& \omega_{6}=0.3 X_{1}+60.0 X_{2}+3.0 X_{3}
\end{aligned}
$$

\section{3) For the third blend}

$$
\begin{aligned}
& \omega 6 / \omega 3=5 / 1 \\
& \omega_{6}=51.5 X_{1}+57.0 X_{2}+55.6 X_{3} \\
& \omega_{6}=0.3 X_{1}+5.6 X_{2}+3.0 X_{3}
\end{aligned}
$$

\section{IMPLEMENTATION OF THE PROGRAM OF THE \\ AutOMATED SCIENTIFIC RESEARCH SYSTEM RESULTS AND DISCUSSION}

Computer modeling using the "brute force" method for the NP problem class allows you to get a complete set of solutions, to make the choice of the optimal solution from the resulting set to achieve the specified constraints and goals.

The method used allows to:

1) Get a complete set of solutions to the problem and suitability for obtaining any other blends and their relationship.

2) Get a sufficient amount of data (with an accuracy of $1 \%)$ to select optimal blends from a variety of computer solutions.

The information basis of a computer program is a database of the chemical composition of vegetable oils. It includes characteristics such as fat content, saturated fatty acids (EFA), monounsaturated fatty acids (MUFA), PUFA, and vitamin E (alpha-tocopherol). The database provides for the search of vegetable oils for a specific attribute. As an example in Fig. 2 information on the content of omega- 6 and omega-3 in oils is provided.
Restrictions on the maximum concentration of oil in a blend, as well as the numerical value to which the objective function should strive are set in the program window (Fig. 3).

The computer system provides the ability to export the results in MS Excel. In Fig. 4, one of the alternative solutions for the operation of an automated research system is presented.

As a result of the work of the automated research system, about 300 blends of vegetable oils were generated. A detailed and reasonable analysis of the results of the calculated data led to the following conclusions:

For the first blend (mustard oil, pumpkin oil and milk thistle oil) and the second blend (sunflower oil, linseed oil and milk thistle oil) the ratio of omega-6: omega-3 can reach values of 5: 1 and above. Consequently, this blend can be used for therapeutic and prophylactic nutrition.

For the third blend (sunflower oil, wheat germ oil and milk thistle oil), the omega- 6 / omega- 3 ratio can reach values of 10 : 1 and above. Therefore, the third blend can only be used for healthy eating.

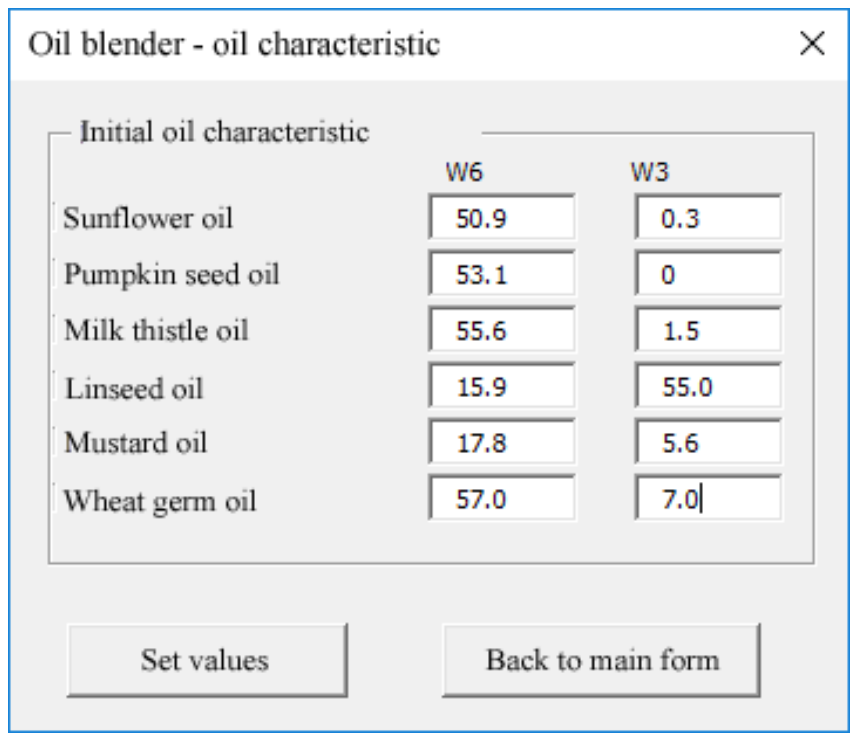

Fig. 2. Fragment of the Russian Version of the Database "Characteristics of Oils on the Composition of Omega-6 and Omega-3 PUFA".

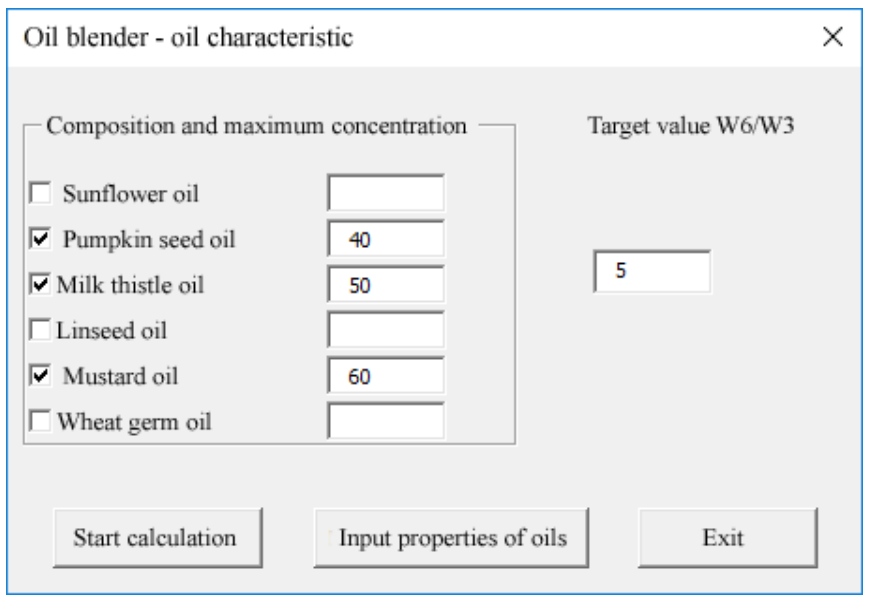

Fig. 3. Input of Initial Data into the Program. 


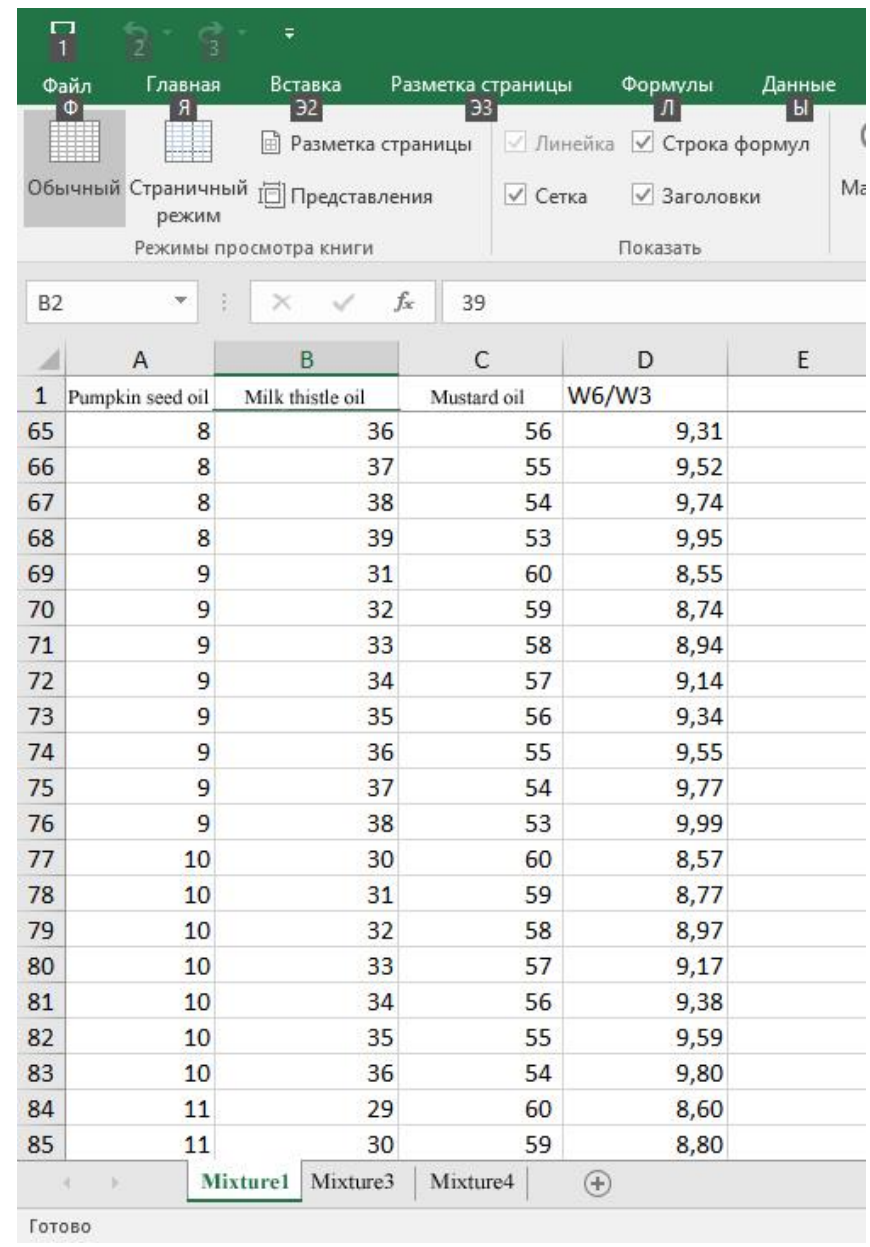

Fig. 4. Data Export to MS Excel. the Results of the Automated Research System for the №1 Blend.

TABLE. III. COMPONENT COMPOSITIONS OF BLENDS OF VEGETABLE OILS AND THE RATIO OF OMEGA-6 / OMEGA-3 PUFA OBTAINED FOR THEM

\begin{tabular}{|l|l|l|l|}
\hline & Blend 1 & Blend 2 & Blend 3 \\
\hline Sunflower oil & - & 60 & 2 \\
\hline Mustard oil & 58.27 & - & - \\
\hline Pumpkin oil & 40 & - & - \\
\hline Linseed oil & - & 14.24 & - \\
\hline Wheat germ oil & - & - & 90 \\
\hline Milk Thistle oil & 1.73 & 25.76 & 8 \\
\hline Omega-6 / omega-3 ratio & 5 & 5 & 10 \\
\hline
\end{tabular}

The results of mathematical design and structural optimization of the composition of vegetable blends are shown in Table III.

Creating a blend of vegetable oils that combine high biological value, good aromatics (organoleptics) and compensate the lack of omega- 6 and omega- 3 requires: selection of components of the formulation; knowledge of structural relationship and principles of food combinatorics. All this knowledge was taken into account when creating an automated system. The use of the system allows to model prescription formulations of blends of oils, taking into account the prescripted limits and the specified goal. In the study three alternative blend compositions with an omega-6: omega-3 ratio in the first and second variant 5: 1 were obtained from the proposed range of vegetable oils, and 10: 1 in the third, which makes it possible to use them for healthy and healthypreventive nutrition.

\section{CONCLUSION}

As a result of the research conducted on the basis of biomedical requirements, the choice of potential ingredients for blending vegetable oils was justified; compositions of vegetable oils of a given quality and properties are designed. Mathematical models of designed blends were developed in the form of a set of criteria and restrictions. One of the main limitations in the problem being solved was the level of maximum concentration of ingredients, so that in the resulting blend, none of the plant components would prevail over the others and, accordingly, could not negatively affect the organoleptic properties of the finished composition (the target function was the omega- 6 to omega-3 ratio). As a result, with the help of information technology that implement the methods of mathematical programming, namely, the method of complete enumeration (brute force), three optimal alternative versions of the composition of vegetable oils were designed.

As subsequent tasks for the study, it would be advisable to develop an integrated large-scale updated database of the fatty acid composition of various vegetable and animal oils for wider possibilities in the design of blends. It would also be important to be able to use different optimization criteria (across the entire spectrum of the distinctive properties of vegetable oils) when making blends depending on the tasks set.

\section{ACKNOWLEDGMENT}

The work was carried out with the financial support of the Russian Foundation for Basic Research in the framework of grant No. 19-016-00049 "Development of a software system for automated calculation of the composition of flour mixtures of functional and dietary nutrition".

\section{REFERENCES}

[1] Ivashkin, Yu.A. Information Technologies for Food Design / Yu.A. Ivashkin, S.B. Yudina, M.A. Nikitina, N.G. Azarova // Meat industry. 2000. - No. 5. - P. 40-41.

[2] Ostryakov, A.N. Blended vegetable oil - a functional food product / A.N. Ostryakov, M.V. Kopylov // Successes in modern science. - 2011. No. 7. - P. 171-172.

[3] Skoryukin A.N. Technology of production and application of blended products with the optimal composition of PUFA: PhD thesis. - Moscow, 2004. - 24 p.

[4] Tutelyan, V.A., Nechaev A.P., Kochetkova A.A. Functional fatty foods in the nutritional structure / V.A. Tutelian, A.P. Nechaev, A.A. Kochetkova // Oil and fat industry. - 2009. - No. 6. - P. 6-9.

[5] Birbasova A.V. Theoretical and experimental substantiation of the formulations of blended functional oils: PhD thesis. -Krasnodar, 2016. $24 \mathrm{p}$.

[6] Levachev M.M. The value of fat in the diet of a healthy and sick person: a guide to dietetics / ed. V.A. Tutelyan, M.A. Samsonova. M., 2002.

[7] Grushina, E.N. On the mechanisms of action of PUFAs on the immune system / E.N. Sruschina, O.K. Mustarina, V.L. Volgarev // Nutrition. 2003. - №3. - pp.35-39.

[8] Ipatova L.G., Kochetkova A.A., Nechaev A.P., Tutelyan V.A. Fatty foods for a healthy diet. Modern look. M., 2009. 396 p.

[9] Usatnikov, S.V. Evaluation of the effectiveness of using a computer program in creating mixtures of vegetable oils for a healthy diet / S.V. Usatnikov, T.I. Timofeyenko, O.V. Rudenko, S.N. Nikonovich, A.V. 
Birbasova, D.A. Ovgareva // Fundamental research. - 2015. - №10 (2).p. 314-317.

[10] Nikolaeva, S.V. Application of the linear programming method for optimization of mixtures of vegetable oils / S.V. Nikolaev, E.A. Klyushina, E.V. Gruzinov, T. Shlyonskaya // Fat-and-oil industry.-2007. - № 1. - p. 23-24.

[11] Voskanyan, O.S. The current state and development trends in the production of emulsion food / O.S. Voskanyan, V.Kh. Paronyan, T.V. Shlenskaya. - M .: Pishepromizdat, 2003. - 353 p.

[12] Ipatova, O.M. The biological activity of linseed oil as a source of omega-3 alpha-linolenic acid / OM. Ipatova, N.N. Prozorovskaya, V.S. Baranova, D.A. Gusev // Biomedical chemistry. - 2004. - T. 50. - No. 1. - P. 25-43.

[13] Zharinov, A.I. Experimental computer modeling of mayonnaise formulations // A.I. Zharinov, M.Yu. Popova, M.A. Nikitin, V.Yu. Mayauska // Fat-and-oil industry. - 2008. - № 1. - p. 34-37.
[14] Patent RUS No. 2402911from 28.05.2009 N.N. Prozorovskaya, D.A. Guseva, A.V. Shironin, M.A. Sanzhakov, E.G. Tikhonova, O.M. Ipatova Vegetable oil based on a mixture of flax, sesame and milk thistle seeds with a ratio of PUFA omega-3 and omega-6 (1: 1.4: 1.6) and methods for its preparation // patent for invention RUS № 2402911, 2009.

[15] RUS patent No. 2402911ot 28.05.2009 N.N. Prozorovskaya, D.A. Guseva, A.V. Shironin, M.A. Sanzhakov, E.G. Tikhonova, O.M. Ipatova Vegetable oil based on a mixture of flax, sesame and milk thistle seeds with a ratio of PUFA omega-3 and omega-6 (1: 6: 81.6) and methods for its preparation // patent for invention RUS No. 2402912, 2009.

[16] Certificate of state computer program No. 2015660121 O.V. Rudenko, T.I. Timofeyenko, S.N. Nikonovich, A.V. Birbasova, D.A. Ovgareva, S.V. Usatnikov. // Optimization of the composition of fatty acids of vegetable oils for therapeutic and dietary preventive nutrition / Computer № 2015660121 from 07.27.2015.

[17] Thomas H. Cormen et al.,. Introduction to Algorithms. - MIT Press, 2001. - P. 1292. - ISBN 978-0-262-03384-8. 